\title{
Prevalence and pattern of occupational exposure to whole body vibration in Great Britain: findings from a national survey
}

\author{
Keith T Palmer, Michael J Griffin, Holly Bendall, Brian Pannett, David Coggon
}

\begin{abstract}
Objectives-To estimate the number of workers in Great Britain with significant occupational exposure to whole body vibration (WBV) and to identify the common sources of exposure and the occupations and industries where such exposures arise.
\end{abstract}

Methods-A postal questionnaire was posted to a random community sample of 22194 men and women of working age. Among other things, the questionnaire asked about exposure to $\mathrm{WBV}$ in the past week, including occupational and common non-occupational sources. Responses were assessed by occupation and industry, and national prevalence estimates were derived from census information. Estimates were also made of the average estimated daily personal dose of vibration (eVDV).

Results-From the 12907 responses it was estimated that 7.2 million men and 1.8 million women in Great Britain are exposed to WBV at work in a 1 week period if the occupational use of cars, vans, buses, trains, and motor cycles is included within the definition of exposure. The eVDV of >374 000 men and 9000 women was estimated to exceed a proposed British Standard action level of $15 \mathrm{~ms}^{-1.75}$. Occupations in which the estimated exposures most often exceeded $15 \mathrm{~ms}^{-1.75}$ included forklift truck and mechanical truck drivers, farm owners and managers, farm workers, and drivers of road goods vehicles. These occupations also contributed the largest estimated numbers of workers in Great Britain with such levels of exposure. The highest estimated median occupational eVDVs were found in forklift truck drivers, drivers of road goods vehicles, bus and coach drivers, and technical and wholesale sales representatives, among whom a greater contribution to total dose was received from occupational exposures than from non-occupational ones; but in many other occupations the reverse applied. The most common sources of occupational exposure to WBV are cars, vans, forklift trucks, lorries, tractors, buses, and loaders.

Conclusions-Exposure to whole body vibration is common, but only a small proportion of exposures exceed the action level proposed in British standards, and in many occupations, non-occupational sources are more important than those at work. The commonest occupational sources of WBV and occupations with particularly high exposures have been identified, providing a basis for targeting future control activities.

(Occup Environ Med 2000;57:229-236)

Keywords: whole body vibration; population; prevalence; exposure

Exposure to whole body vibration (WBV) arises in workers who operate tractors, excavators, bulldozers, forklift trucks, armoured vehicles, lorries, and many other vehicles and machines. Although knowledge is incomplete, a growing body of evidence indicates that such exposure to vibration and jolting may cause an increased risk of low back pain. ${ }^{1-6}$

To control the hazard satisfactorily, there is a need for up to date information on the sources and extent of exposure nationally in different occupational groups, and on the associated morbidity. However, in Britain little relevant information is available. In a large community survey of back pain in 1992, 7\% of respondents reported having been drivers of trucks, tractors, diggers, and other industrial vehicles. ${ }^{7}$ More recently a questionnaire on self reported working conditions was administered to a random sample of 2230 employed adults selected from a national postcode address file. ${ }^{8}$ Twelve per cent of men $(95 \%$ confidence interval (95\% CI) $9 \%$ to $14 \%$ ) and $1 \%$ of women $(95 \%$ CI $0.5 \%$ to $2 \%$ ) reported that their job sometimes involved sitting or standing on a vibrating machine or vehicle, the prevalence of exposure being highest in farming, fishing and forestry, and in road transport. However, no detailed information was collected on the range and extent of exposures, the relative contribution of occupational and leisure time exposures to total dose, or the effect of such exposures on health.

As part of a large community survey of exposure to vibration, we have collected information on the frequency and extent of exposures to WBV, to allow national estimates of the prevalence and distribution of relevant exposures in Great Britain.

\section{Methods}

A questionnaire was posted to a sample of 21201 men and women of working age from the patient lists of 34 general practices and to 993 members of the armed services. The details are reported fully in an accompanying 
paper. ${ }^{9}$ In brief, the practices were chosen to give a broad geographical coverage of Great Britain, and the posting was split over a summer and the following winter to assess any seasonal differences in reporting. Members of the armed forces were included in a separate mailing, and were selected at random from central pay records.

The questionnaire included sections on current occupation and industry, and exposures to WBV at work in the previous 7 days (sources and durations of exposure). ${ }^{10}$ Information on current occupational exposure to WBV was obtained principally from a question about driving or riding any of 26 listed vehicles and machines at work in the past week, but also from a supplementary open question. Information was also collected on the durations of exposure to common everyday sources of WBV (cars, vans, buses, coaches, trains, and motorcycles) during leisure and journeys to and from work in the past week.

The occupations and industries of respondents were coded according to two standardised schemes. ${ }^{11} 12$ Then, to derive national estimates, prevalence estimates from the sample were directly standardised according to the occupational distribution (or in some analyses the industrial distribution) of the latest (1991) census. $^{9}$

An equivalent estimated dose of vibration (eVDV) was calculated for each exposed respondent by assigning frequency weighted vibration accelerations ( $a_{\mathrm{wz}}$ values) to each category of vehicles or machines from a reference list and assuming the time dependency proposed in British Standard 6841, 1987. ${ }^{13}$ Further details are provided in an appendix. Separate estimates were made for occupational and leisure time sources of exposures, enabling the relative importance of occupational and non-occupational exposures to be assessed.

Table 1 Most common occupational sources of exposure to whole body vibration in the past week

\begin{tabular}{|c|c|c|c|c|}
\hline \multirow[b]{2}{*}{ Vehicle or machine } & \multicolumn{2}{|c|}{ Sample } & \multicolumn{2}{|c|}{$\begin{array}{l}\text { Estimated numbers with exposure in } \\
\text { Great Britain (in thousands) }\end{array}$} \\
\hline & $n$ & $\begin{array}{l}\text { Reporting exposure } \\
\text { in the sample }\end{array}$ & $n$ & $95 \% C I$ \\
\hline \multicolumn{5}{|l|}{ Ment: } \\
\hline Car & 1729 & 31.5 & 4101 & 3941 to 4262 \\
\hline Van & 947 & 17.2 & 2254 & 2123 to 2385 \\
\hline Fork lift truck & 512 & 9.3 & 1209 & 1110 to 1309 \\
\hline Lorry & 378 & 6.9 & 730 & 659 to 802 \\
\hline Tractor & 255 & 4.6 & 588 & 517 to 658 \\
\hline Bus & 237 & 4.3 & 450 & 393 to 506 \\
\hline Loader & 146 & 2.7 & 361 & 303 to 419 \\
\hline Train & 134 & 2.4 & 301 & 250 to 351 \\
\hline Dumper & 102 & 1.9 & 297 & 240 to 354 \\
\hline Excavator & 93 & 1.7 & 275 & 220 to 330 \\
\hline Other aircraft & 157 & 2.9 & 193 & 163 to 223 \\
\hline Off road car or van & 145 & 2.6 & 128 & 107 to 149 \\
\hline Helicopter & 118 & 2.1 & 125 & 102 to 147 \\
\hline Armoured vehicle & 100 & 1.8 & 67 & 54 to 80 \\
\hline \multicolumn{5}{|l|}{ Women‡: } \\
\hline Car & 595 & 15.3 & 1361 & 1259 to 1463 \\
\hline Bus & 149 & 3.8 & 371 & 312 to 429 \\
\hline Van & 80 & 2.1 & 162 & 127 to 197 \\
\hline Train & 47 & 1.2 & 99 & 71 to 128 \\
\hline
\end{tabular}

$\star$ Percentage of employed respondents who rode on or drove a given vehicle or machine in the week.

tAll others $\leqslant 1.5 \%$ of employed male respondents.

$\ddagger$ All others $\leqslant 1 \%$ of employed female respondents.
In some cases exposure information was missing, either because a representative $a_{\mathrm{wz}}$ value could not be assigned or because the duration of exposure to a particular source was not reported. However, where the subjects concerned had been exposed to several sources of WBV, it was often possible to estimate a minimum eVDV.

\section{Results}

DISTRIBUTION AND RETURNS OF QUESTIONNAIRES Altogether, 22415 subjects were selected for study, but 221 were excluded on their general practitioners' advice (because of bereavement or terminal illness), so that 22194 questionnaires were posted. Usable responses were obtained from 12907 subjects, including 9084 people who been at work in the week preceding completion of the questionnaire. The response patterns are described elsewhere. ${ }^{9}$

FREQUENCY OF EXPOSURE TO WHOLE BODY VIBRATION

A total of 3081 men $(56.1 \%$ of those in employment) reported having been occupationally exposed to WBV in the week preceding completion of the questionnaire. The prevalence of exposure was similar in those who did and did not require a letter of reminder. The estimated 1 week prevalence of exposure among men of working age in the national population was $35.1 \%$ (95\% CI 34.3 to $36.0 \%$ ) overall, or $54.6 \%$ (95\% CI 53.3 to $55.9 \%$ ) of those at work.

This corresponded to a total of 7197000 (95\%CI 7026000 to 7369000 ) men exposed. The occupations that contributed the largest estimated numbers of exposed men were: drivers of road goods vehicles (424000 exposed, 95\%CI 412000 to 436 000), managers and proprietors of service industries (259 000, 95\%CI 215000 to 304 000), metal working, production and maintenance fitters, (246 000 95\%CI 216000 to 275000 ), production workers and maintenance managers (229 000 95\% CI 190000 to 269000 ), technical and wholesale sales representatives (170 000, 95\% CI 149000 to 191000 ), and motor mechanics and auto engineers (174000, 95\%CI 161000 to 187000$)$. The industries which contributed the largest estimated numbers of exposed men were: construction (965000 men exposed, 95\% CI 892000 to 1038000 ), public administration and defence $(523000,95 \% \mathrm{CI} 473000$ to $573000)$, and land transport (494 000, 95\% CI 459000 to 529000 ).

Among women, 753 (19.4\% of employed women in the sample) had been exposed in the past week, and again the prevalence differed little according to the need or otherwise for a reminder. The 1 week prevalence of exposure in the national population was estimated as $7.9 \%(95 \%$ CI 7.4 to $8.4 \%)$ of all women and $17.2 \%$ (95\% CI 16.1 to $18.3 \%)$ of those in work.

The 1 week prevalence of occupational exposure to WBV in women corresponded to an estimated 1783000 (95\% CI 1667000 to 1899 000) exposed nationally. The occupa- 


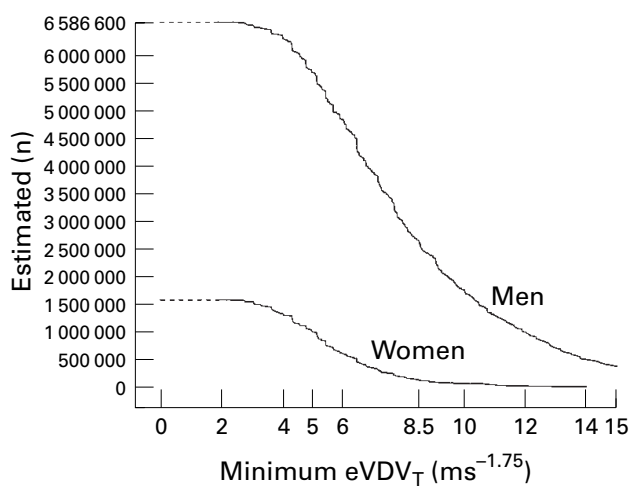

Figure 1 Minimum estimated numbers of men and women in Great Britain whose daily equivalent estimated dose of vibration (eVDV) from all occupational sources in the past week exceeded the values indicated.

tions with the largest estimated number of exposed women were nurses (116000 exposed, $95 \%$ CI 90000 to 143000 ), sales assistants (108 000, 95\% CI 77000 to 140 000), secretaries, personal assistants, and word processing operators $(62000,95 \%$ CI 37000 to 88000 ), and managers and proprietors in service industries $(55000,95 \% \mathrm{CI}$ 29000 to 82000 ). The principal industries in which women were exposed were: health and social work (418 000, 95\%CI 361000 to $474000)$ and the retail trade $(200000,95 \% \mathrm{CI}$ 155000 to 245000 ).

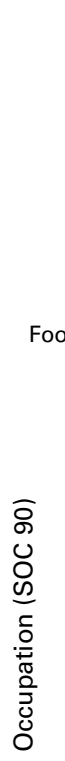

Marketing and sales managers (121)

Production workers (110)

Machine tool operatives (840)

Managers in service industries (179)

Electricians (521)

Other plant and machine operatives (899)

Food, drink, and tobacco process operatives (809)

Technical and wholesale sales reps (710)

Police officers (sergeant and below) (610)

Carpenters and joiners (570)

Metal working, production fitters (516)

Plumbers, heating engineers (532)

All other labourers (990)

Postal workers and sorters (940)

NCOs, UK armed forces $(600)$

Builders, building contractors (504)

Motor mechanics, auto engineers (540)

Gardeners, groundsmen (594)

Store keepers, warehousemen (441)

Farm workers (900)

Farm owners, horticulturists (160)

Drivers of road goods vehicles (872)

Fork lift, mechanical truck drivers (887)

Bus and coach drivers (873)

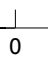

MOST COMMON OCCUPATIONAL SOURCES OF

WHOLE BODY VIBRATION

Table 1 lists the sources of exposure to WBV in the past week that respondents reported most often. Among men, the most common exposures were car $(31.5 \%$ of respondents), van $(17.2 \%)$, forklift truck $(9.3 \%)$, lorry $(6.9 \%)$, tractor $(4.6 \%)$, bus $(4.3 \%)$, and loader $(2.7 \%)$. The national estimates for these sources indicate that there are $>4000000$ occupational users of cars, $>2000000$ occupational users of vans, and $>1000000$ drivers of forklift trucks. Among women, cars, buses, and vans were the sources of exposure reported most often, with around 1.3 million women journeying in a car while at work during the previous week.

In men, lorries were driven for prolonged periods (median time 10 hours in the past week). Other lengthy weekly exposures arose from the use of cars (median time 6 hours) and vans, excavators, off road vehicles, armoured vehicles, and aircraft (median times 4-4.5 hours). In women, the median time for car journeys during work over the past week was 4 hours.

PERSONAL LEVELS OF EXPOSURE

Among 2301 exposed men from the sample who supplied full information, 836 (15.3\% of male respondents) indicated exposures calculated to correspond with a daily average $>8.5$

Exposure $>$ minimum eVDV $\mathrm{T}_{\mathrm{T}}=15.0 \mathrm{~ms}^{-1.75}$ $\square$ Exposure $>$ minimum eVDV $_{\mathrm{T}}=8.5 \mathrm{~ms}^{-1.75}$

Figure 2 Occupations in which significant exposures to whole body vibration most commonly arose in the past week among employed men. 


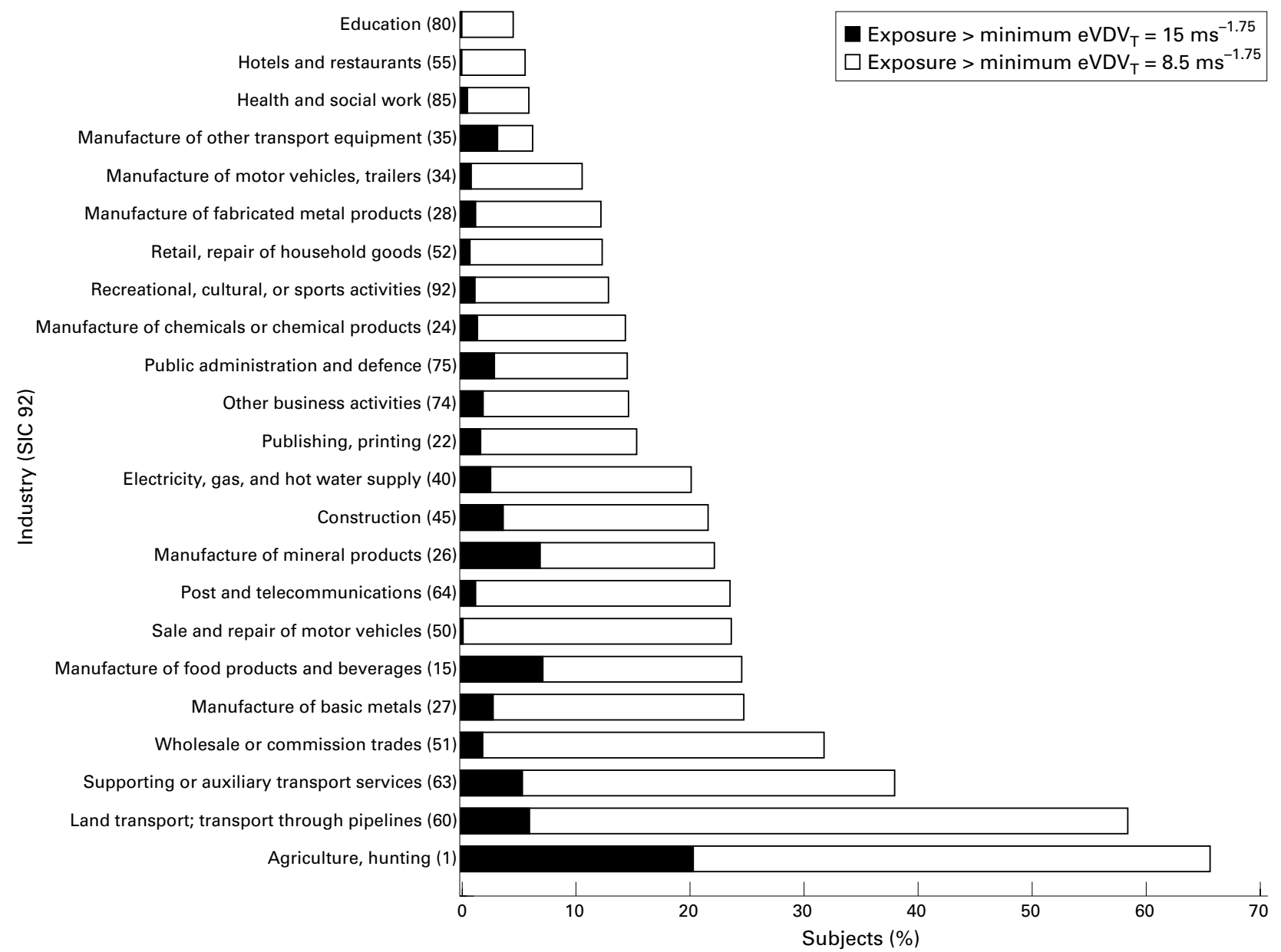

Figure 3 Industries in which significant exposures to whole body vibration most commonly arose in the past week among employed men.

$\mathrm{ms}^{-1.75}$ - the lower boundary of the health guidance caution zone suggested in International Standards Organisation (ISO) $2631,1997 .{ }^{20}$ These included 114 men $(2.1 \%$ of male respondents) whose estimated exposure exceeded the action level of $15 \mathrm{~ms}^{-1.75}$ which is proposed in British standard 6841. ${ }^{19}$ Among 616 exposed women providing full information, the corresponding figures were 42 (exposed $>8.5 \mathrm{~ms}^{-1.75}$ ) and two $\left(>15 \mathrm{~ms}^{-1.75}\right.$ ).

Exposure information was incomplete for 780 men and 137 women exposed to WBV (either because of missing durations of exposure or missing data on representative vibration magnitudes), but in workers who were exposed to several sources of WBV, sufficient information was provided to suggest that at least a further 79 men and a further four women had a minimum eVDV $>15 \mathrm{~ms}^{-1.75}$. On this basis, the minimum number of men in the national population exceeding this action level was estimated to be at least 374000 (95\% CI 322000 to 426000$)$, and the estimated number of women was 9000 (95\% CI 2000 to 17 000). Figure 1 presents further details in the form of a cumulative frequency curve of the estimated numbers in the population exceeding different minimum values of eVDV in the past week.

The proportion of workers by occupation and industry with significant levels of exposure is illustrated in figures 2 and 3. Among men, the occupations in which minimum estimated dose most often exceeded $15 \mathrm{~ms}^{-1.75}$ were forklift truck and mechanical truck drivers (42\%), farm owners and managers $(31 \%)$, farm workers $(27 \%)$, non-commissioned officers in the United Kingdom armed forces (11\%), and drivers of road goods vehicles $(9 \%)$. Exposures were most often estimated to exceed $8.5 \mathrm{~ms}^{-1.75}$ in drivers of buses and coaches (95\%), forklift trucks $(91 \%)$, and roads goods vehicles $(86 \%)$, and in farm owners (78\%) and farm workers $(76 \%)$.

Table 2 presents estimates of the minimum numbers of men by occupation nationally with exposures $>15 \mathrm{~ms}^{-1.75}$ in the past week. Farm owners and managers (52 000), drivers of roads goods vehicles (39 000), and forklift truck drivers (34000) contributed the greatest numbers by occupation; whereas workers in agriculture (67 000), construction (55 000), and land transport (34000) contributed most by industry.

Table 3 presents the occupations in men with the highest median occupational estimated dose values. To examine the relative importance of leisure time exposures, the separate contribution to total eVDV from common non-occupational exposures was also estimated. The median eVDV from all sources combined was $6.4 \mathrm{~ms}^{-1.75}$ (interquartile range (IQR) 5.1-8.4). The median leisure time value $\left(5.4 \mathrm{~ms}^{-1.75}\right)$ exceeded the corresponding occupational estimate $\left(2.7 \mathrm{~ms}^{-1.75}\right)$, but among men 
Table 2 Minimum prevalence of exposure to whole body vibration ( $\mathrm{eVDV} \mathrm{T}_{\mathrm{T}}>15 \mathrm{~ms}^{-1.75}$ ) in the past week by occupation and industry in men

\begin{tabular}{|c|c|c|c|c|c|c|}
\hline & \multicolumn{3}{|c|}{ Sample } & \multicolumn{3}{|c|}{$\begin{array}{l}\text { Population of Great Britain (in thousands): } \\
\text { minimum }^{*} \text { estimated with exposure }>15 \mathrm{~ms}^{-1.75}\end{array}$} \\
\hline & \multirow[b]{2}{*}{$n$} & \multicolumn{2}{|c|}{ Minimum ${ }^{\star}$ with exposure $>15 \mathrm{~ms}^{-1.75}$} & \multirow[b]{2}{*}{$n$} & \multirow{2}{*}{\multicolumn{2}{|c|}{$95 \% C I$}} \\
\hline & & $n$ & $\%$ & & & \\
\hline \multicolumn{7}{|l|}{ Occupation (SOC 90): } \\
\hline All occupations & 5490 & 193 & 3.5 & 374 & 322 to 42 & \\
\hline Farm owners and managers, horticulturists $(160)$ & 36 & 11 & 30.6 & 52 & 26 to 7 & 78 \\
\hline Drivers of road goods vehicles (872) & 157 & 14 & 8.9 & 39 & 19 to & 58 \\
\hline Forklift and mechanical truck drivers (887) & 33 & 14 & 42.4 & 34 & 21 to & 48 \\
\hline Farm workers $(900)$ & 51 & 14 & 27.5 & 22 & 12 to & 31 \\
\hline Store keepers and warehousemen (441) & 94 & 7 & 7.4 & 18 & 5 to & 30 \\
\hline $\begin{array}{l}\text { Non-commissioned officers and other ranks, UK } \\
\text { armed forces (600) }\end{array}$ & 571 & 65 & 11.4 & 17 & 13 to 2 & 21 \\
\hline \multicolumn{7}{|l|}{ Industry (SIC 92): } \\
\hline Agriculture, hunting and related service activities (1) & 154 & 31 & 20.1 & 67 & 46 to & 88 \\
\hline Construction (45) & 428 & 15 & 3.5 & 55 & 28 to & 83 \\
\hline Land transport; transport through pipelines $(60)$ & 137 & 8 & 5.8 & 34 & 11 to & 57 \\
\hline $\begin{array}{l}\text { Public administration and defence; compulsory social } \\
\text { security (75) }\end{array}$ & 299 & 8 & 2.7 & 24 & 8 to 4 & 40 \\
\hline Manufacture of food products and beverages (15) & 102 & 7 & 6.9 & 21 & 6 to 3 & 36 \\
\hline
\end{tabular}

$\star$ Minimum values are presented because in some cases exposure information was missing. Analysis has been restricted to occupations with $\geqslant 30$ subjects and industries with $\geqslant 60$ subjects.

counted as having occupational exposure to WBV in the past week the total eVDV was higher (median $8.2 \mathrm{~ms}^{-1.75}$, IQR 6.7-10.6), and the median occupational exposure $\left(7.4 \mathrm{~ms}^{-1.75}\right)$ exceeded the median leisure time value (5.4 $\left.\mathrm{ms}^{-1.75}\right)$. The highest median occupational values were found in men driving forklift trucks, buses and coaches, and road goods vehicles, and among technical and wholesale sales representatives. A wide spread of values was estimated for several of these occupations. In women, the median occupational eVDVs were zero, and $92 \%$ of respondents were estimated to incur greater exposure outside work than in employment, as were $53 \%$ of the women who reported occupational exposure in the past week.

REPRESENTATIVENESS OF EXPOSURES TO WHOLE BODY VIBRATION IN THE PAST WEEK

To determine whether there were seasonal differences in exposure, a comparison was made between the summer time and winter time responses. The overall prevalence of exposure was similar in the two periods (in men $43.1 \% \mathrm{v}$ $43.6 \%$, and in women $11.7 \% v 12.9 \%$ ). Men from the winter posting were somewhat more likely to have an eVDV $>15 \mathrm{~ms}^{-1.75}(2.6 \% \mathrm{v}$
$1.6 \%$ ), but only minor differences were found among women.

Nine per cent of those reporting exposure (280 men and 70 women) stated that the past week had not been typical of their job. Among 141 men who supplied further particulars, 89 indicated that the exposure had been greater than normal, and 52 that it had been less. Among 22 women who provided more information, 13 reported that exposure was normally less and nine said it was usually more.

\section{Discussion}

Our findings indicate that in Great Britain some 9000000 people are exposed on a weekly basis to occupational sources of WBV, and highlight the principal occupations in which exposures occur, the major sources of exposure, and the contribution of leisure time activities to total dose of eVDV.

These estimates need to be considered in the light of possible biases and errors. We have argued elsewhere ${ }^{9}$ that the study sample is likely to have been adequately representative, given the large sample size, the wide geographical distribution and the completeness of family doctors' registers; and, moreover, a process of standardisation was used to compensate for differences in sampling and response rates by

Table 3 Relative contributions of occupational and leisure time exposure to total exposure (eVDV $V_{T}$ in employed men

\begin{tabular}{|c|c|c|c|c|c|}
\hline \multirow[b]{2}{*}{ Occupation (SOC 90) } & \multirow[b]{2}{*}{$n^{\star}$} & \multicolumn{3}{|c|}{ Median (interquartile range) of eVDV $V_{T}$} & \multirow{2}{*}{$\begin{array}{l}\text { Occupational } \\
\text { >leisure } \\
\text { exposure } \\
n(\%)\end{array}$} \\
\hline & & Occupational & Leisuret & All sources & \\
\hline All men & 4584 & $2.7(0.0-7.4)$ & $5.4(4.3-6.3)$ & $6.4(5.1-8.4)$ & $1632(36)$ \\
\hline Men with no occupational exposure & 2283 & $0.0(0.0-0.0)$ & $5.2(4.3-6.2)$ & $5.2(4.3-6.2)$ & $0(-)$ \\
\hline Men with occupational exposure & 2301 & $7.4(5.7-10.0)$ & $5.4(4.6-6.4)$ & $8.2(6.7-10.6)$ & $1632(71)$ \\
\hline Forklift and mechanical truck drivers (887) & 30 & $14.9(11.8-16.2)$ & $5.4(4.8-6.1)$ & $14.9(11.8-16.4)$ & $29(97)$ \\
\hline Drivers of road goods vehicles (872) & 128 & $12.8(11.3-13.5)$ & $4.9(4.3-5.8)$ & $12.9(11.7-13.6)$ & $125(98)$ \\
\hline Bus and coach drivers (873) & 33 & $11.1(10.7-11.4)$ & $5.0(4.3-6.3)$ & $11.2(11.0-11.6)$ & $33(100)$ \\
\hline Technical and wholesale sales representatives (710) & 40 & $7.7(6.4-8.3)$ & $4.9(4.3-6.4)$ & $8.1(7.4-8.8)$ & $29(72)$ \\
\hline Police officers (sergeant and below) (610) & 44 & $7.0(5.1-8.4)$ & $5.7(5.1-6.4)$ & $8.1(6.7-9.6)$ & $25(57)$ \\
\hline Other sales representatives, not elsewhere classified (719) & 43 & $6.8(5.3-7.8)$ & $5.0(4.3-6.4)$ & $7.7(6.2-8.6)$ & $30(70)$ \\
\hline Store keepers and warehousemen (441) & 78 & $6.6(0.0-11.6)$ & $5.3(4.6-6.3)$ & $7.8(5.4-11.9)$ & $43(55)$ \\
\hline Motor mechanics, autoengineers (including road patrol engineers) (540) & 34 & $6.5(4.8-9.9)$ & $5.9(5.1-6.4)$ & $7.6(6.3-10.7)$ & $21(62)$ \\
\hline Postal workers, mail sorters $(940)$ & 35 & $6.0(0.0-9.5)$ & $5.4(4.6-6.3)$ & $7.7(5.7-9.6)$ & $16(46)$ \\
\hline Marketing and sales managers (121) & 67 & $5.9(0.0-7.6)$ & $5.4(4.8-6.4)$ & $7.2(6.0-8.4)$ & $31(46)$ \\
\hline
\end{tabular}

*Excludes subjects with partial or no occupational exposure information.

†Use of car, van, bus, train, or motor cycle in commuting and non-work journeys.

Analysis is confined to men at work in the past week. The data are ranked by occupational VDV. 
Table 4 Exposure to whole body vibration: comparison of this and the survey of self reported working conditions ${ }^{8}$

\begin{tabular}{|c|c|c|c|c|c|c|c|}
\hline \multirow[b]{2}{*}{ Occupational group * } & \multirow{2}{*}{$\begin{array}{l}\text { Working } \\
\text { conditions } \\
\text { survey } \\
1995 \\
(\%)\end{array}$} & \multicolumn{2}{|c|}{$\begin{array}{l}\text { Definition 1: all } \\
\text { vehicles }\end{array}$} & \multicolumn{2}{|c|}{$\begin{array}{l}\text { Definition 2: all } \\
\text { vehicles except car }\end{array}$} & \multicolumn{2}{|c|}{$\begin{array}{l}\text { Definition } 3: t \\
\text { industrial vehicles }\end{array}$} \\
\hline & & $n$ & $\%$ & $n$ & $\%$ & $n$ & $\%$ \\
\hline \multicolumn{8}{|l|}{ Men: } \\
\hline All occupations & 12 & 3081 & 56 & 2156 & 39 & 1289 & 23 \\
\hline Professional and related supporting management & 4 & 167 & 51 & 48 & 14 & 17 & 5 \\
\hline Teaching & 0 & 24 & 16 & 17 & 11 & 2 & 1 \\
\hline Nursing & 0 & 5 & 18 & 1 & 4 & 0 & 0 \\
\hline Other education and welfare & 0 & 82 & 53 & 22 & 14 & 3 & 2 \\
\hline Literary, artistic and sports & 0 & 29 & 51 & 16 & 28 & 9 & 16 \\
\hline Science and engineering & 6 & 186 & 46 & 84 & 21 & 39 & 10 \\
\hline Managerial & 4 & 306 & 57 & 134 & 25 & 67 & 12 \\
\hline Clerical & 2 & 122 & 39 & 58 & 18 & 10 & 3 \\
\hline Secretarial & 0 & 3 & 14 & 2 & 9 & 0 & 0 \\
\hline Selling & 5 & 136 & 60 & 55 & 24 & 16 & 7 \\
\hline Security and protective services & 22 & 478 & 66 & 402 & 56 & 276 & 38 \\
\hline \multicolumn{8}{|l|}{ Women: } \\
\hline All occupations & 1 & 753 & 19 & 304 & 8 & 74 & 2 \\
\hline Professional and related supporting management & 2 & 65 & 29 & 17 & 8 & 7 & 3 \\
\hline Teaching & 1 & 38 & 16 & 22 & 10 & 1 & 0 \\
\hline Nursing & 0 & 66 & 27 & 14 & 6 & 0 & 0 \\
\hline Other education and welfare & 0 & 74 & 38 & 19 & 10 & 0 & 0 \\
\hline Literary, artistic and sports & 0 & 12 & 28 & 4 & 9 & 2 & 5 \\
\hline Science and engineering & 0 & 14 & 24 & 6 & 10 & 4 & 7 \\
\hline Managerial & 2 & 63 & 24 & 24 & 9 & 6 & 2 \\
\hline Clerical & 0 & 79 & 12 & 33 & 5 & 4 & 1 \\
\hline Secretarial & 0 & 28 & 8 & 7 & 2 & 1 & 0 \\
\hline Selling & 0 & 55 & 16 & 20 & 6 & 2 & 1 \\
\hline Security and protective services & 0 & 47 & 52 & 28 & 31 & 16 & 18 \\
\hline Catering & 0 & 19 & 9 & 8 & 4 & 1 & 0 \\
\hline Care workers & 0 & 63 & 19 & 26 & 8 & 0 & 0 \\
\hline Hair and beauty & 0 & 16 & 29 & 1 & 2 & 1 & 2 \\
\hline
\end{tabular}

^As defined in the survey on self reported working conditions in 1995, appendix $2 .{ }^{8}$

tRock crushers, concrete production machinery, tractors, loaders, excavators, bulldozers, graders, scrapers, dumpers, road rollers, mowers, off road forestry vehicles, armoured vehicles, forklift trucks, mobile cranes, lorries, helicopters, other aircraft, high speed boats, hoists or lifts, ambulances, boats, off road cars or vans, quad bikes, fire engines, milk floats, conveyor belts, or agricultural vehicles.

occupation; and major response bias seems unlikely, given the similarity of estimates of exposure in people who responded with and without a reminder.

A separate supporting study suggests that workers generally report their exposures to WBV accurately. ${ }^{15}$ However, a concern particular to the assessment of WBV is that recreational exposures might sometimes be reported as if they were incurred at work. The scope for this error is greatest for common means of private and public transport, as the distinction between using these vehicles at work (occupationally) as compared with journeys to and from work (non-occupationally) may be one that subjects fail to draw. In keeping with this, in our supporting study, a smaller proportion of work time exposures to the car in the past week were confirmed as feasible than for other sources of WBV. To explore this further, a check was performed to determine the occupations of people reporting prolonged work time exposure to cars, buses, coaches, trains, and motor cycles. In most cases the occupations were ones in which such levels of exposure were plausible - for example, chauffeurs, taxi drivers, and bus and train drivers-so large scale overreporting of exposure to these sources is considered unlikely.

None the less, the reporting of exposure to public and private transport vehicles has an important impact on the estimated numbers with exposure. To illustrate the size of effect, three alternative definitions of exposure are presented in table 4, the first encompassing all of the vehicles counted in the survey; the second excluding use of cars; and the third confined solely to industrial vehicles and machines. For comparison, information is provided on the reported prevalence of exposure by occupation in the survey of self reported working conditions. ${ }^{8}$ In professional managers and education and welfare workers, a substantial proportion of those exposed were classified as such solely on the basis of car use, whereas in other groups, such as farming, fishing and forestry, coal mining, road transport, and material moving and storing, few of those with exposure reported cars as the only source. The most restrictive definition resulted in a much lower estimate of frequency of exposure overall $(23 \%$ $v 56 \%$ for all men), and in specific occupational groups - for example, in professional and related support managers, 5\% v 51\%-but the estimated prevalences of exposure were generally higher than those in the survey of self reported working conditions. That community survey differed in several respects from our own, being based on a smaller (but randomly chosen) sample and on interviews rather than a postal questionnaire. It was also undertaken in a different calendar period; but the difference in findings is most likely to be accounted for by a difference in the questions used. In the survey of self reported working conditions exposure was ascertained by the single question: "Does/ did your job ever involve you sitting or standing on a vibrating machine or in a vibrating vehicle?", by contrast with our own checklist of sources. Respondents may not have considered cars, vans, buses, coaches, trains, and motor cycles to be included within the scope of the earlier survey's question, and may have also had difficulties in identifying or recalling 
relevant, substantive exposures in the absence of a clearer prompt, in which case our estimates may be more reliable.

Estimates of personal exposure are subject to several sources of error. ${ }^{16}$ The measurement of $a_{\mathrm{wz}}$ vibration was based on a subjective choice, and single values were chosen whereas the true magnitude will vary between vehicles that differ in model type, age, source of manufacture, seating, and tyre characteristics; and between similar vehicles which are used for different tasks, or driven over different surfaces, or at different speeds. To test the appropriateness of our choices, sample measurements were made on common sources of exposure,${ }^{17}$ and in general the median measured values were close to those assigned (listed in the appendix). Only weekly exposure information was available, and so an average estimate of dose was made on the assumption that daily durations of exposure were sufficiently similar for the average to predict the likely risk, but in practice the relative importance of daily exposure pattern as a risk factor for back pain is not clear. Finally, estimates of personal doses of exposure relied on self estimates of duration of exposure, but empirical data from our accompanying paper suggest that this is reasonable, given the good general agreement between reported and observed exposure times. ${ }^{15}$

The data relate to exposures in the previous week, and this might convey a misleading impression of annual exposure in occupations where levels of exposure vary markedly by season. There will also have been people, especially users of cars, trains, buses, and planes, who were exposed unusually in the past week-for example, people attending occasional meetings. However, as estimates of reported exposure were similar in the winter and summer and few people reported their exposures to be unusual, these factors are not thought to have had a large impact.

\section{Conclusions}

Occupational exposures to WBV are common in Great Britain, with an estimated 7200000 men and 1800000 women exposed in a 1 week period. Only a small proportion of exposures exceed the action level (eVDV >15 $\mathrm{ms}^{-1.75}$ ) proposed in British standards, but this represents an estimated minimum of 374000 men and 9000 women with such levels of exposure nationally. The commonest occupational sources of WBV have been identified, as have the occupations where particularly high exposures arise - providing a basis for targeting future control activities. However, in many occupations, non-occupational sources make a more important contribution to exposure.

This study was supported by a grant from the Health and Safety Executive. We are grateful to the Royal College of General Practitioners, the Primary Care Rheumatology Society, HM Armed Forces, the general practices that helped with the postArmed Forces, the general practices that helped with the postng, and the MRC staff who were involved in data handling particularly Ian Bowes and Vanessa Cox. Paul Brereton an Chris Nelson offered many const Gould prepared this manuscript.
Table 5 Representative $a_{v v}$ values assigned to vehicles and machines in the survey

\begin{tabular}{ll}
\hline Vehicle or machine & $a_{w i}\left(\mathrm{~ms}^{-2}\right.$ r.m.s. $)$ \\
\hline Car & 0.5 \\
Van & 0.7 \\
Bus & 0.6 \\
Train & 0.5 \\
Motor cycle & 1.0 \\
Rock crusher & 0.7 \\
Concrete production machinery & 1.5 \\
Tractor & 0.75 \\
Loader & 1.2 \\
Excavator & 0.6 \\
Bulldozer & 0.75 \\
Grader & 0.75 \\
Scraper & 1.5 \\
Dumper & 1.2 \\
Road roller & 1.0 \\
Mower & 0.65 \\
Off road forestry vehicle & 0.75 \\
Armoured vehicle & 1.2 \\
Forklift truck & 0.9 \\
Mobile crane & 0.3 \\
Lorry & 0.7 \\
Helicopter & 0.8 \\
Other aircraft & 0.5 \\
High speed boat & 1.5 \\
Hoist or lift & 0.3 \\
Bicycle & 1.0 \\
Ambulance & 0.7 \\
Boat & 0.2 \\
Off road car or van & 1.5 \\
Quad bike & 1.5 \\
Fire engine & 0.7 \\
Milk float & 1.0 \\
Conveyor belt (mine) & 0.7 \\
Agricultural vehicle & 1.5 \\
Miscellaneous & - \\
Unclassifiable & - \\
& \\
\hline
\end{tabular}

- No value assigned (either because of insufficient data, or because members of the group were considered too dissimilar).

\section{Appendix: derivation of personal vibration exposure levels}

An equivalent estimated dose of vibration (eVDV) was calculated by assigning frequency weighted vibration r.m.s. accelerations for vertical vibration on a seat $\left(a_{\mathrm{wz}}\right.$ values) to each category of vehicle from a reference list (table 5), and assuming the time dependency proposed in British Standard 6841. ${ }^{13}$ Hence:

$\mathrm{eVDV}_{\mathrm{i}}=1.4 \mathrm{a}_{\mathrm{wzi}}\left[\frac{60 \mathrm{t}_{\mathrm{i}}}{5}\right]^{\frac{1}{4}}$

where:

$\mathrm{eVDV}_{\mathrm{i}}=$ the daily equivalent vibration magnitude for $i$ th vehicle

$a_{\mathrm{wij}}=$ the frequency weighted acceleration in the vertical axis for the $i$ th vehicle

$t_{i}=$ total duration of exposure in minutes over the whole week.

And for several machines or vehicles used in combination:

$\operatorname{eVDV}_{\mathrm{T}}=\left[\sum_{\mathrm{i}=1}^{\mathrm{i}=\mathrm{n} \mathrm{eVDV}_{\mathrm{i}}^{4}}\right]^{\frac{1}{4}}$

where:

$\mathrm{n}=$ the number of vehicles

$\mathrm{eVDV}_{\mathrm{T}}=$ the average 8 hour equivalent magnitude (total daily estimated vibration dose value) for all $n$ vehicles combined

$\mathrm{eVDV}_{\mathrm{i}}=$ the daily equivalent vibration magnitude for $i$ th vehicle.

These expressions assume that the daily durations of exposure in the past week were sufficiently similar on each day for the average to indicate the likely risk. 
The $\mathrm{a}_{\mathrm{wz}}$ values have been assembled from a variety of sources including:

1 International Social Security Association (ISSA). Vibration at work. Paris, France: International Section Research, Institut National de Recherche et de Securite (INRS), 1989.

2 Griffin MJ. Handbook of human vibration. London: Academic Press, 1990. (ISBN: 0-12-303040-4.)

3 Internet resources, including National Institute for Working Life Database in Sweden. Located at: http:// umetech.niwl.se.

4 Discussion with specialist inspectors from the UK Health and Safety Executive.

For each vehicle several values were usually available, and an attempt was made to select values that appeared appropriate in relation to common expected patterns of use. The range of vibration magnitudes can vary greatly according to the conditions of operation, but the choices made tended generally to accord with median values we have recently measured and reported. ${ }^{17}$

1 Kelsey JL. An epidemiological study of acute herniated lumbar intervertebral discs. Rheumatol and Rehabilitation 1975;14:144-58.

2 Backman AL. Health survey of professional drivers. Scand $\mathcal{F}$ Work Environ Health 1983;9:30-5.

3 Bongers PM, Boshuizen HC, Hulshof CTJ, et al. Back disBongers PM, Boshuizen HC, Hulshof CTJ, et al. Back dis-
orders in crane operators exposed to whole-body vibration. orders in crane operators exposed to whole-body

4 Bongers PM, Hulshof CTJ, Dijkstra L, et al. Back pain and exposure to whole body vibration in helicopter pilots. Ergonomics 1990;33:1007-26.

5 Bovenzi M, Zadini A. Self-reported low back symptoms in urban bus drivers exposed to whole-body vibration. Spine 1992;17:1048-59.
6 Pietri F, Leclerc A, Boitel L, et al. Low-back pain in Pietri F, Leclerc A, Boitel L, et al. Low-back pain in
commercial drivers. Scand $\mathcal{7}$ Work Environ Health 1992;18: comm

7 Walsh K, Cruddas M, Coggon D. Interaction of height and mechanical loading of the spine in the development of lowback pain. Scand f Work Environ Health 1991;17:420-4.

8 Jones JR, Hodgson JT, Osman J. Self-reported working conditions in 1995. London: The Stationery Office, 1997.

9 Palmer KT, Griffin MJ, Bendall H, et al. Prevalence and pattern of occupational exposure to hand transmitted vibration in Great Britain: findings from a national survey. Occup Environ Med 2000;57:218-28.

10 Palmer K, Coggon D, Pannett B, et al. The development of a self-administered questionnaire to assess exposures to hand-transmitted and whole-body vibration and their health effects. Fournal of Sound and Vibration 1998;215: 653-86.

11 Office of Population Censuses and Surveys. Standard occupational classification 1990. London: The Stationery Office, 1990.

12 Office of National Statistics. Indexes to the standard industrial classification of economic activities 1992. London: The classification of economic

13 British Standards Institution. Measurement and evaluation of human exposure to whole-body mechanical vibration and repeated shock. London: BSI, 1987. (British Standard BS 6841.)

14 International Organization for Standardization. Guide for the valuation of human exposure to whole body vibration - part 1: general requirements. London: ISO, 1997. (ISO 2631-1.)

15 Palmer KT, Haward B, Griffin MJ, et al. Validity of self reported occupational exposures to hand transmitted and whole body vibration. Occup Environ Med 2000;57:237-41.

16 Griffin MJ. Handbook of human vibration, [appendix 5]. London: Academic Press, 1990.

17 Paddan GS, Haward BM, Griffin MJ, et al. Whole-body vibration: evaluation of some common sources of exposure in Great Britain. London: Health and Safety Executive, The Stationery Office, 1999. (Contract Research Report
235/1999.) 